\title{
Obtenção, caracterização e uso de genipina como agente reticulante de hidrogeis de
}

\section{quitosana}

\author{
Obtaining, characterizing and using genipin as a crosslinking agent for chitosan hydrogels \\ Obtención, caracterización y uso de genipina como reticulante de hidrogeles de quitosano
}

Recebido: 25/07/2021 | Revisado: 30/07/2021 | Aceito: 03/08/2021 | Publicado: 08/08/2021

Rafael Braga da Cunha

ORCID: https://orcid.org/0000-0003-0304-4220 Universidade Federal de Campina Grande, Brasil E-mail: rafaelbragadacunha@gmail.com

João Emidio da Silva Neto

ORCID: https://orcid.org/0000 -0001-5290-2741 Universidade Federal de Campina Grande, Brasil E-mail: joao.emidio@certbio.ufcg.edu.br

Bruna de Freitas Leite

ORCID: https://orcid.org/0000-0002-6107-0323 Universidade Estadual da Paraíba, Brasil

E-mail: brunadefleite@gmail.com

José Filipe Bacalhau Rodrigues

ORCID: https://orcid.org/0000-0002-3916-6214

Universidade Federal de Campina Grande, Brasil

E-mail: filipe.rodrigues@certbio.ufcg.edu.br

Maria Roberta de Oliveira Pinto

ORCID: https://orcid.org/0000-0002-2151-3564

Universidade Estadual da Paraíba, Brasil E-mail: roberta1_oliveira@hotmail.com

Marcus Vinicius Lia Fook

ORCID: https://orcid.org/0000-0002-8566-920X

Universidade Federal de Campina Grande, Brasil

E-mail: marcus.liafook@certbio.ufcg.edu.br

\begin{abstract}
Resumo
Uma variedade de hidrogéis, que correspondem a uma classe de materiais poliméricos altamente hidratados, estão sendo empregados como biomateriais. De modo particular, hidrogéis de quitosana, destaca-se por ser uma matriz adesiva que apresenta, propriedades antibacterianas, osteogênicas e não toxidade. E são capazes de reter, liberar e distribuir agentes terapêuticos no local de aplicação. A produção de hidrogéis à base de quitosana tem sido alcançada por meio da mistura de soluções de quitosana com agentes reticulantes ou polímeros carregados sob condições de reações específicas. O reagente mais comumente utilizado é o glutaraldeído, no entanto, apresenta elevada citotoxicidade, e por isso, vem sendo substituídos por reticulantes menos tóxicos, e biologicamente seguros, a exemplo da genipina, um reagente natural. Portanto, o objetivo deste trabalho foi promover a extração e purificação da genipina na forma sólida a partir de frutos verdes de Jenipapo, realizando sua identificação por meio de cromatografia de camada delgada (CCD), espectrometria de massa, espectroscopia na região do infravermelho com transformada de Fourier (FTIR) e quantificação por análise gravimétrica. E a produção de hidrogéis de quitosana usando a genipina obtida, como agente reticulante. As amostras obtidas, foram caracterizadas por absorção de água, Calorimetria Exploratória Diferencial (DSC), FTIR e Reologia. A genipina extraída apresentou $0,47 \%$ de rendimento extrativo, enquanto os hidrogéis produzidos com $3 \%$ de genipina apresentaram um perfil característico de gel polimérico.
\end{abstract}

Palavras-chave: Hidrogéis; Genipina; Quitosana; Agente reticulante.

\begin{abstract}
A variety of hydrogels, which correspond to a class of highly hydrated polymeric materials, are being used as biomaterials. In particular, chitosan hydrogels stand out for being an adhesive matrix that presents antibacterial, osteogenic and non-toxic properties. And they are able to retain, release and deliver therapeutic agents at the application site. The production of chitosan-based hydrogels has been achieved by mixing chitosan solutions with crosslinking agents or charged polymers under specific reaction conditions. The most commonly used reagent is glutaraldehyde, however, it has high cytotoxicity, and therefore, it has been replaced by less toxic and biologically safe crosslinkers, such as genipin, a natural reagent. Therefore, the objective of this work was to promote the extraction and purification of genipin in solid form from green fruits of Jenipapo, carrying out its identification through thin layer chromatography
\end{abstract}


(TLC), mass spectrometry, infrared spectroscopy with transform Fourier test (FTIR) and quantification by gravimetric analysis. And the production of chitosan hydrogels using the obtained genipin as a crosslinking agent. The samples obtained were characterized by water absorption, Differential Scanning Calorimetry (DSC), FTIR and Rheology. The extracted genipin showed $0.47 \%$ extractive yield, while the hydrogels produced with $3 \%$ genipin showed a characteristic profile of a polymeric gel.

Keywords: Hydrogels; Genipine; Chitosan; Crosslinking agent.

\section{Resumen}

Se están utilizando como biomateriales una variedad de hidrogeles, que corresponden a una clase de materiales poliméricos altamente hidratados. En particular, los hidrogeles de quitosano destacan por ser una matriz adhesiva que presenta propiedades antibacterianas, osteogénicas y no tóxicas. Y son capaces de retener, liberar y administrar agentes terapéuticos en el sitio de aplicación. La producción de hidrogeles a base de quitosano se ha logrado mezclando soluciones de quitosano con agentes reticulantes o polímeros cargados en condiciones de reacción específicas. El reactivo más comúnmente utilizado es el glutaraldehído, sin embargo, tiene una alta citotoxicidad y, por lo tanto, ha sido reemplazado por reticulantes menos tóxicos y biológicamente seguros, como el genipin, un reactivo natural. Por tanto, el objetivo de este trabajo fue promover la extracción y purificación de genipina en forma sólida a partir de frutos verdes de Jenipapo, realizando su identificación mediante cromatografía en capa fina (TLC), espectrometría de masas, espectroscopia infrarroja con transformada prueba de Fourier (FTIR) y cuantificación mediante análisis gravimétrico. Y la producción de hidrogeles de quitosano utilizando la genipina obtenida como reticulante. Las muestras obtenidas se caracterizaron por absorción de agua, Calorimetría Diferencial de Barrido (DSC), FTIR y Reología. La genipina extraída mostró un rendimiento extractivo del $0,47 \%$, mientras que los hidrogeles producidos con genipina al $3 \%$ mostraron un perfil característico de un gel polimérico.

Palabras clave: Hidrogeles; Genipino; Quitosano; Agente de reticulación.

\section{Introdução}

O Jenipapo é o fruto do jenipapeiro, árvore da espécie Genipa americana Linnaeus oriunda do noroeste da América do Sul e distribuída de norte a sul do Brasil, principalmente encontrada em matas mais úmidas, ou próximas a rios (Francis, 1993). O jenipapo é utilizado como pintura corporal por nativos na América do Sul, isso porque, do néctar do fruto verde, se extrai uma tinta de coloração azul-escura que serve para pintar paredes, pele, cerâmicas, dentre outros. (Renhe, I. R. T. et al, 2009).

No ano de 1960, Djerassi e colaboradores descobriram o (Metil (1S,2R,6S)-2-hidroxi-9-(hidroximetil)-3oxabiciclo[4.3.0]nona-4,8-dieno-5-carboxilato), conhecido comercialmente como genipina. A genipina é um composto orgânico conhecida como a aglicona do geniposídeo. A diferença entre o geniposídeo e a genipina se dá principalmente na estrutura do carbono 1 do hexano, onde o geniposídeo, apresenta uma glicose e a genipina uma hidroxila. É preciso considerar que ambas, genipina e geniposídeo, são substâncias polares e suas concentrações variam de acordo com a parte do fruto. Portanto, uma vez que o foco é a obtenção da genipina, é preciso diminuir os riscos da extração de geniposídeo e isso pode ser feito por meio da utilização das partes ricas na primeira substância e pobres na segunda (Velásquez, 2014).

A genipina é um agente natural de ativação ou reticulante, que pode ser associada covalentemente a diversos materiais para elevar sua estabilidade física e química e prover a possibilidade de reações biofuncionais, sendo empregada na imobilização de enzimas, liberação gradativa de fármacos, bioadesivos na constituição de próteses para aumentar a resistência mecânica de ossos e cartilagens, no tratamentos de ferimentos cutâneos, entre outros. Essa substância ainda apresenta atividades contra danos por oxidação e trombose, ação antimicrobiana e anti-inflamatória, protege o hipocampo dos neurônios, doenças hepáticas e diabetes, e gera corantes estáveis para indústria têxtil e alimentícia. (Velásquez; Rivas; Ocanto, 2014; Ramos-de-La-Penã el al., 2016; Bellé, 2017; Neves; Meireles, 2018).

Diversas são as técnicas de extração da genipina, podendo elas serem empregadas de forma isolada, combinada ou sequenciada. As três principais técnicas conhecidas são: hidrolise enzimática (ação de $\beta$-glicosidases), solventes (geralmente utilizado em sistema aquoso bifásico) e ultrassom (ondas ultrassônicas propiciam o rompimento de células e a formação de 
cavitações na parte interna do material empregado (Yang et al. 2011; Wang et al. 2012; Winotapun et al. 2013; Dong et al. 2014; Zhu et al. 2014).

A genipina apresenta estabilidade entre os pHs 4 e 9 e ótima solubilização em solventes, principalmente em etanol, éter dietílico e propilenoglicol. Apesar de ser uma substância mais hidrofóbica que o geniposídeo, ela ainda possui capacidade de se solubilizar em meios aquosos (Djerassi et al. 1960; Ramos-de-la-Peña et al. 2016).

O uso de genipina, como agente reticulante, na obtenção de hidrogéis, vem sendo relatada para aplicações voltadas a engenharia de tecidos, principalmente acelerando o processo de cicatrização de feridas, utilizando como base à fibroina, celulose e quitosana. Os géis obtidos pelo complexo genipina-quitosana possuem características desejáveis para aplicação na imobilização de enzimas, pois a genipina gera uma estabilização nas cadeias da quitosana promovendo um aumento na resistência mecânica do derivado (Zhu et al., 2015; Bellé, 2017).

Conforme dito anteriormente, a genipina pode ser utilizada como reticulante, substituindo polímeros convencionais utilizados em imobilizações enzimáticas, inclusive, em substituição à glutaraldeído que possui elevada citotoxicidade. Estudos têm demostrado a sinergia entre a característica de agente reticulante da genipina, usada na preparação de hidrogéis, com suas propriedades curativas, que promove aceleração no processo de cicatrização em ferimentos e favorece a regeneração de tecidos (Bellé, 2017).

Dentre os polímeros naturais mais estudados em processos de regeneração de pele, destaca-se a quitosana. Este polissacarídeo apresenta ação antimicrobiana (bactericida, bacteriostática, fungicida e fungistática) e de redução no tempo de cicatrização de lesões provenientes de agressões físicas a tecidos animais, como por exemplo, ferimentos ou queimaduras (Craveiro, 2000). Além disso, a quitosana é biodegradável (Lee; Ha; Park, 1995), biocompatível (Rao; Sharma, 1997) e confere excelente resistência mecânica aos biomateriais produzidos a partir de seu uso (Mima et al., 1983). Além disso, a quitosana pode ser utilizada na preparação de hidrogéis poliméricos.

A produção de hidrogéis à base de quitosana ocorre através da mistura de soluções de quitosana com reticulantes ou polímeros carregados sob condições específicas, tais como pH e temperatura, para formar um gel viscoso (Vunain; Mishra; Mamba, 2017). Os hidrogéis formados in situ através de reticulação física tem recebido notável atenção, por não envolver componentes tóxicos. Entretanto, uma das maiores desvantagens dessa reticulação consiste na baixa propriedade mecânica que limita suas aplicações. Visando uma melhoria nas propriedades, hidrogéis formados com quitosana tem sido reticulado quimicamente, através de ligações covalentes com diferentes reagentes, tais como: glutaraldeído (Yu et al., 2017), formaldeído ou epóxi (Ornoff et al., 2016). No entanto, estes reagentes apresentam toxicidade, e vem sendo substituídos por reticulantes menos tóxicos, e biologicamente seguros como a genipina, um reagente natural (Xu et al., 2015).

O uso de genipina, como agente reticulante, na obtenção de hidrogéis, vem sendo relatada para aplicações voltadas a engenharia de tecidos, principalmente acelerando o processo de cicatrização de feridas, utilizando como base à fibroina, celulose e quitosana (Chronopoulou et al., 2018; Sun et al., 2018). Os géis obtidos pelo complexo genipina-quitosana possuem características desejáveis para aplicação na imobilização de enzimas, pois a genipina gera uma estabilização nas cadeias da quitosana (Pellá et al., 2018), promovendo um aumento na resistência mecânica do derivado (Yao et al., 2012).

Por tanto, este trabalho tem como objetivo extrair e purificar a genipina obtida pelo método adaptado de Velásquez (2009), e utilizá-la como agente reticulante na produção de hidrogeis de quitosana-genipina. Desta forma, este trabalho se faz necessário, visto que, avalia as propriedades físicas, químicas e reológicas da genipina como agente reticulante de hidrogéis de quitosana, e propõe soluções de baixo custo para a extração dessa substância, favorecendo à aplicação de tais hidrogéis na área médica, em especial, no tratamento da regeneração de tecidos. 


\section{Materiais e Métodos}

O trabalho em questão trata-se de uma pesquisa laboratorial de abordagem quantitativa baseado em Estrela, C. (2018) e Pereira et al. (2018), onde a extração e purificação da genipina foi baseada na metodologia adaptada de Veslásquez (2014), enquanto a síntese dos hidrogeis seguiu a metodologia aplicada por Marinho (2016). A extração da genipina, a síntese dos hidrogeis e os ensaios de caracterização foram realizados no laboratório de avaliação e desenvolvimento de biomateriais do nordeste - CERTBIO.

\subsection{Materiais}

- Frutos verdes de Jenipapo (Genipa americana L.);

○ Ácido Clorídrico (HCl) (37\%; Neon);

- Acetona P.A. (P.A.; Dinâmica);

○ Éter de petróleo (P.A; Dinâmica);

○ Clorofórmio (99,8\%; Neon);

○ Diclorometano (99,5\%; Vetec);

- Acetato de Etila (P.A.; Química Moderna)

\subsection{Processo de extração e identificação da genipina no extrato}

Três frutos verdes (Figura 1A), de tamanhos e pesos semelhantes, foram cortados (Figura 1B) ao meio e despolpados (Figura 1C) com auxílio de uma faca e uma espátula de inox. O endocarpo e as sementes foram misturados para serem pesadas. A amostra da polpa pesada (Figura 1D) foi então colocada em um béquer de plástico, onde foi acidificada e macerada com um pistilo de porcelana. Em seguida, foi acrescido clorofórmio à mistura (relação de 3:1 do peso despolpado), com maceração contínua até que as sementes estivessem o mais separadas possível da polpa.

Esta foi então armazenada em um frasco Erlenmeyer de 2000mL (Figura 1E) e foi colocada sob agitação moderada. Como a locomoção do agitador é dificultada pela presença da grande quantidade de sólidos suspensos, uma agitação manual em sentido horário e anti-horário foi realizada em intervalos de cinco minutos por um tempo total de $2 \mathrm{~h}$ e $30 \mathrm{~min}$. A amostra foi então filtrada por gravidade com papel de filtro qualitativo e o extrato filtrado (Figura 1F) foi armazenado em um frasco de vidro âmbar com tampa, coberto com papel alumínio e colocado sob refrigeração até o momento da evaporação do solvente.

O extrato foi concentrado por meio da remoção do solvente em um rota-evaporador (Figura 1G) à temperatura ambiente por 2 horas. O líquido resultante (cor de mel, odor agudo de jenipapo e consistência oleaginosa) foi armazenado em um frasco coletor com tampa (Figura $1 \mathrm{H}$ ) e colocado sob refrigeração até a etapa de precipitação. Antes de realizar o procedimento de precipitação da substância, uma CCD do extrato foi realizada para confirmação de sua presença. Como pode ser visto na Figura 3I, havia grande quantidade de genipina - fato reforçado pela altura do padrão (lado esquerdo) - mas ainda em presença de impurezas. 
Figura 1. Fluxograma de extração da genipina.

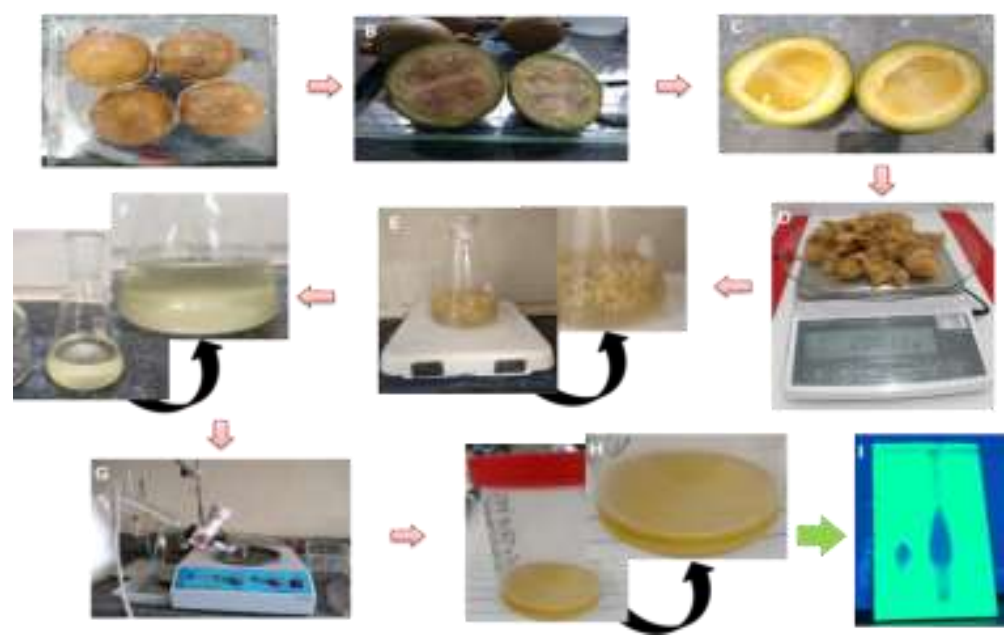

Fonte: Autores.

\subsection{Recuperação, purificação e identificação da genipina sólida}

Ao extrato foi adicionado algumas gotas de acetona P.A. para induzir a precipitação da genipina, seguida da mistura com éter de petróleo (Figura 4I) e filtrado a vácuo. Mais um pouco de éter de petróleo foi adicionado ao frasco do extrato para dissolver o remanescente e lavar o sólido (Figura 2II). O procedimento foi repetido no filtrado e ambos os sólidos retidos foram misturados. Uma pequena quantidade de amostra foi retirada e uma nova CCD (Figura 2III) realizada para mapear a remoção das impurezas. Em comparação a CCD do extrato bruto concentrado pode ser observado que houve uma diminuição da presença de impurezas.

O sólido foi raspado do papel de filtro (Figura 2II) e colocado em um novo frasco coletor, onde foi misturado ao diclorometano (Figura 2IV). Um banho-maria foi preparado (Figura 2V) e o frasco foi submetido à aquecimento brando ( $70^{\circ} \mathrm{C}$ ). Uma vez solubilizado por completo o sólido no solvente, o frasco foi colocado em um banho de gelo (Figura 2VI) até total precipitação da genipina. Realizou-se então uma filtração a vácuo e o resíduo resultante (Figura VII) foi armazenado em novo frasco coletor. A CCD do sólido branco obtido (Figura VIII) demonstrou excelente correspondência com o padrão e ausência de impurezas.

Figura 2. Fluxograma de recuperação da genipina.

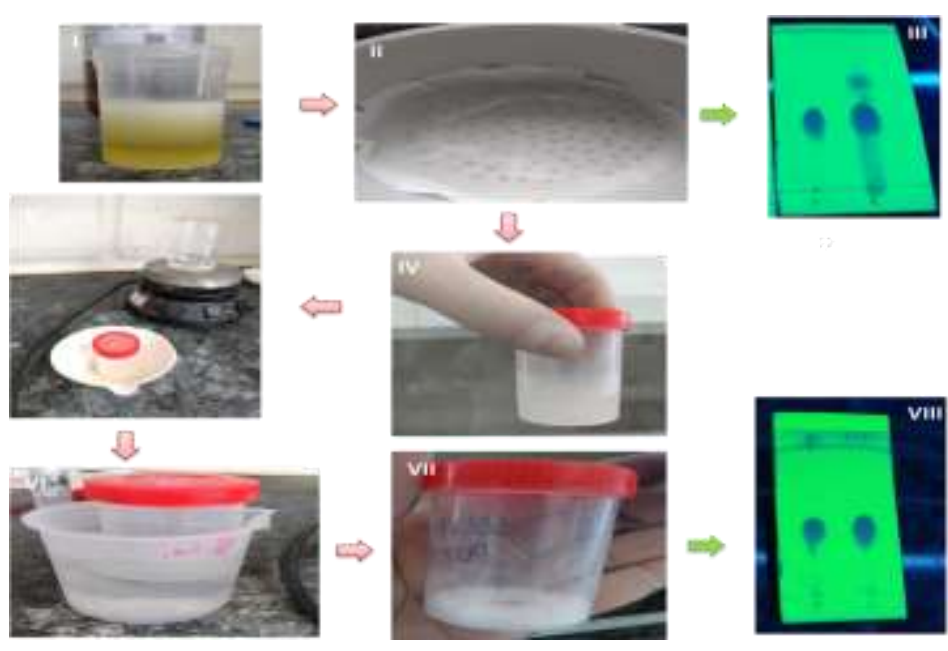

Fonte: Autores. 


\subsection{Síntese de hidrogéis}

A síntese dos hidrogéis de quitosana foi realizada da seguinte forma: oito soluções foram preparadas, cada uma com $4 \mathrm{~g}$ de massa total, com água destilada $(99,5 \%)$ e ácido acético (0,5\%). Em seguida, foi adicionado, a cada uma delas, quitosana em diferentes proporções $(0,9 ; 1,3 ; 1,8$ e $3 \%)$. As soluções foram agitadas até se dissolverem completamente e depois centrifugadas. Em etapa posterior, essas mesmas soluções foram replicadas e adicionadas duas quantidades diferentes de genipina $(0,03$ e $0,3 \%)$, mais uma vez, as amostras foram agitadas e centrifugadas.

Tabela 1 - Composições dos hidrogéis de quitosana e genipina.

\section{LISTA DE COMPOSIÇÕES REALIZADAS}

\begin{tabular}{l|r}
\hline COMPOSIÇÃO A & $0,9 \%$ Quitosana $0,03 \%$ Genipina \\
COMPOSIÇÃO B & $1,8 \%$ Quitosana $0,3 \%$ Genipina \\
COMPOSIÇÃO C & $0,9 \%$ Quitosana $0,3 \%$ Genipina \\
COMPOSIÇÃO D & $1,8 \%$ Quitosana $0,03 \%$ Genipina \\
COMPOSIÇÃO E & $1,3 \%$ Quitosana $0,03 \%$ Genipina \\
COMPOSIÇÃO F & $1,3 \%$ Quitosana $0,3 \%$ Genipina \\
COMPOSIÇÃO G & $3 \%$ Quitosana $0,03 \%$ Genipina \\
COMPOSIÇÃO H & $3 \%$ Quitosana $0,3 \%$ Genipina \\
\hline
\end{tabular}

Figura 3. Síntese dos hidrogéis.

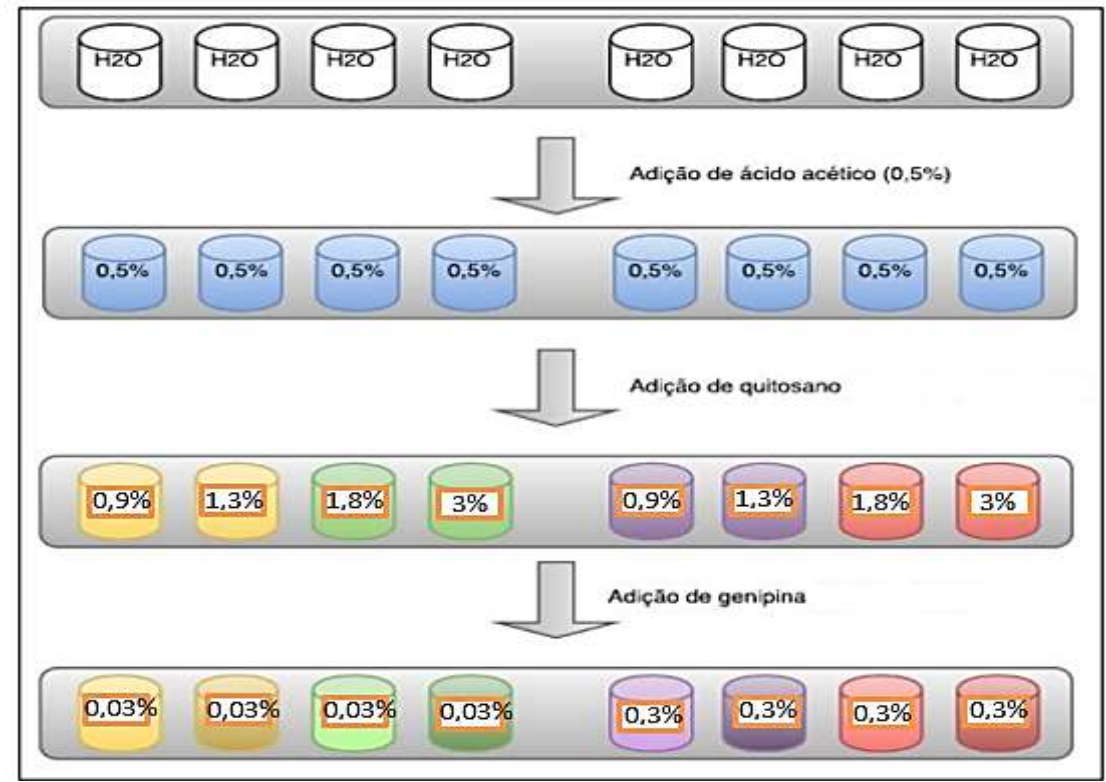

Fonte: Adaptado de Marinho (2016).

\subsection{Técnicas de Caracterização}

\section{- Cromatografia de camada delgada (CCD)}

A análise de CCD foi realizada a partir de frações do extrato obtido, utilizando placas de sílica Gel 60 F254 - MERCK, e como reveladores foram utilizados ultravioleta e o anisaldeído/vanilina sulfúrico. 


\section{○ Espectrometria de massa}

A análise do sólido obtido do processo extrativo foi realizada em espectrômetro de massa da Perkin-Elmer, modelo AxION 2 TOF.

\section{- Espectroscopia na região do infravermelho com transformada de Fourier (FTIR)}

Os Espectros do sólido obtido no processo extrativo, foram obtidos em um espectrômetro da Perkin-Elmer, modelo Spectrum 400 FT-IR no modo ATR com 16 varreduras por espectro.

\section{○ Análise gravimétrica}

A quantificação foi realizada por meio de gravimetria, utilizando frascos coletores vazios e idênticos que armazenarão a substância purificada e o conjunto.

\section{- Absorção de água}

A absorção de água dos hidrogéis foi determinada da seguinte maneira: cerca de 10mg dos hidrogéis liofilizados foram colocados com $2 \mathrm{~g}$ de água deionizada em um tubo próprio e imediatamente, centrifugados durante 30 minutos a $3000 \mathrm{rpm}$. As amostras foram removidas, o excesso de água retirado com papel de filtro, e pesadas.

\section{○ Calorimetria Exploratória Diferencial}

O ensaio foi realizado em equipamento da TA Instruments, modelo DSC Q20. O fluxo de energia trocado entre a amostra e a vizinhança, utilizando uma taxa de aquecimento e resfriamento de $10^{\circ} \mathrm{C} / \mathrm{min}$, sob atmosfera de nitrogênio de 50 $\mathrm{mL} / \mathrm{min}$, foi avaliado utilizando um programa de temperatura em três estágios.

\section{○ Reologia}

Foram realizados testes oscilatórios com frequência $(1 \mathrm{~Hz})$ e tensão (1 Pa) constantes, em um reômetro MARS III da Thermo Scientific, adquirido um ponto a cada 30 segundos, à temperatura ambiente $\left(25^{\circ} \mathrm{C}\right)$. Este teste permitiu avaliar a evolução dos G' e G', de modo a saber quando a amostra gelifica. Visto que, em termos reológicos a gelificação ocorre quando o G' e o G', se intersectam. Também foram aplicados testes rotacionais para a determinação das viscosidades das soluções. Para isso, foram utilizadas rampas de velocidades de forma crescente $\left(0.5-100 \mathrm{~s}^{-1}\right)$, sob variação de temperatura $\left(25\right.$ até $\left.50^{\circ} \mathrm{C}\right)$.

\section{Resultados e discussão}

Os resultados obtidos são apresentados a seguir e se referem à identificação da genipina, quitosana e caracterização dos hidrogéis.

\subsection{Espectroscopia na região do infravermelho com transformada de Fourier (FTIR)}

As amostras extraídas foram submetidas ao ensaio de FTIR com o objetivo de caracterizar em termos de identificação e determinação de características estruturais do extrato a fim de verificar a extração da genipina pura. Os espectros correspondentes a Genipina comercial e a genipina proveniente da extração estão presentes na Figura 4. 
Figura 4. Espectro de FTIR do Padrão Comercial e Genipina da Genipa americana L.

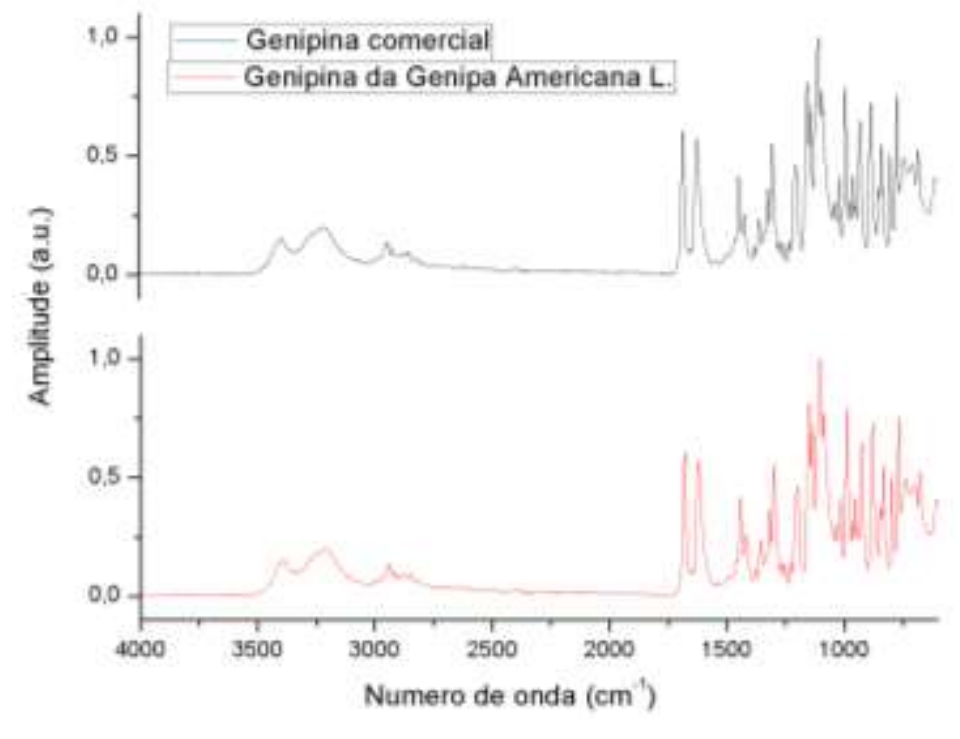

Fonte: Autores.

A Figura 4, exibe os espectros de infravermelho da amostra de genipina comercial e da genipina extraída. Percebe-se que os picos são semelhantes e apresentam bandas características dos grupos funcionais da genipina, como: pico em $3393 \mathrm{~cm}^{-1}$ (OH livre) característico da deformação axial de $\mathrm{OH}$, e um pico em $3213 \mathrm{~cm}^{-1}$ (OH em ligação de hidrogênio); percebe-se uma deformação axial de $\mathrm{C}=\mathrm{C}$ de alcenos (em $1622 \mathrm{~cm}^{-1}$ ); a vibração de $1151 \mathrm{~cm}^{-1}$ e estiramento com formação de pico em $1106 \mathrm{~cm}^{-}$ ${ }^{1}$ são referentes às vibrações C-O e C-O, respectivamente, e a vibração de $1681 \mathrm{~cm}^{-1}$ corresponde ao grupo dos ácidos carboxílicos e são características das C=O (Silverstein e Webster, 2000; Butler e col., 2003). As bandas de absorção características do padrão de genipina comercial não apresentaram diferenças significativas das bandas apresentadas pelas demais amostras.

A Figura 5, exibe os espectros de infravermelho da quitosana utilizada para a formação dos hidrogéis de quitosana genipina. Foi observado que as vibrações de alongamento axial do grupo $\mathrm{OH}$ ocorrem em uma faixa de $3000 \mathrm{a} 3600 \mathrm{~cm}^{-1} . \mathrm{O}_{\text {pico }}$ em $1650 \mathrm{~cm}^{-1}$ refere-se ao grupo carbonilo $\mathrm{C}=\mathrm{O}$, enquanto a banda de absorção em $1591 \mathrm{~cm}^{-1}$ refere-se à vibração dos grupos amida e da deformação dos N-H (Fan et al, 2018).

Figura 5 - Espectro de FTIR da quitosana CERTBIO.

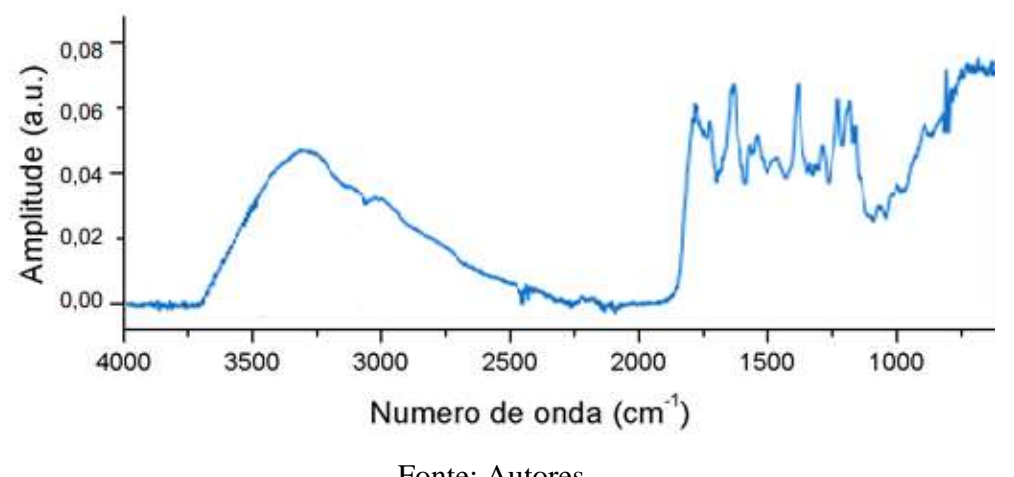

Fonte: Autores.

A Figura 6, refere-se aos espectros de infravermelho dos hidrogéis das composições (B); (C); (F) e (H). A análise foi realizada em apenas quatro das oito composições de hidrogéis, pois, apenas as composições com elevador teor de genipina $(0,3 \%)$ apresentaram um comportamento reológico típico de um gel, enquanto, as demais composições, com baixos teores de genipina $(0,03 \%)$, apresentaram um comportamento típico de uma solução polimérica. 
Figura 6 - Espectro de FTIR dos hidrogéis com 0,3\% de quitosana. Composições (B); (C);(F) e (H).

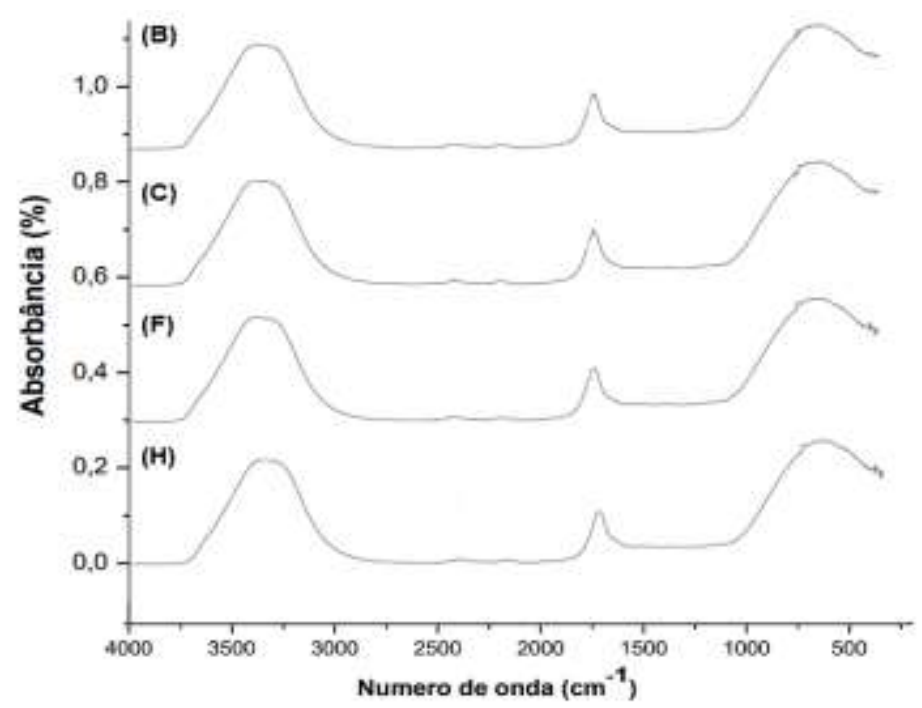

Fonte: Autores.

De acordo com a Figura 6, não foi observado nenhuma diferença significativa entre os espectros de infravermelho dos hidrogéis com $0,3 \%$ de quitosana. No entanto, foi constatado, que ocorreu um crescimento das bandas de vibração do grupo $\mathrm{C}=\mathrm{O}$, em $1650 \mathrm{~cm}^{-1}$ passando para $1630 \mathrm{~cm}^{-1}$. Esse crescimento da banda, indica que ocorreu uma reação entre o carbonil da genipina e o grupo amina da quitosana, reação essa, responsável pela cor azul nos hidrogéis com alto teor de genipina. Demitri et al, 2015 obteve resultados semelhantes com respeito as bandas de absorção de hidrogéis de quitosana e genipina, como também, observou o surgimento da coloração azulada nos hidrogéis.

\subsection{Espectrometria de Massa}

A Figura 7 representa os espectros de massa obtidos:

Figura 7. (A) Espectros de massa da Genipina Padrão e (B) Genipina isolada da Genipa americana L.

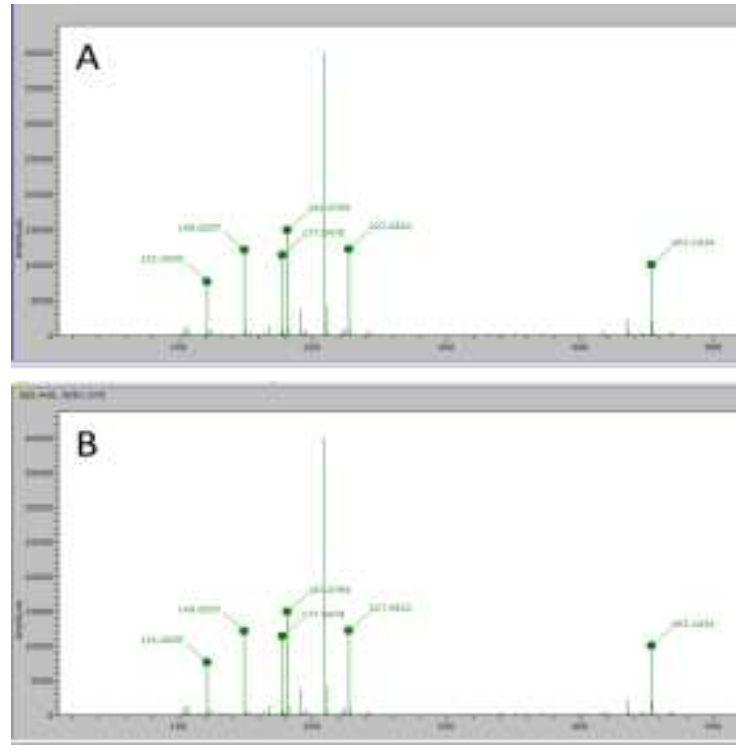

Fonte: Autores. 
A genipina extraída não apresentou diferença significativa nos espectros de massa quando comparada a genipina comercial, resultado esse enfatizado pela identificação realizada através do CCD. Também se comprovou a ausência de contaminações na genipina extraída. Foi possível observar através do espectro um valor massa de 227,0823 que é característico da massa da genipina $[\mathrm{C} 11 \mathrm{H} 14 \mathrm{O} 5+\mathrm{H}]^{+}$. Enquanto que a massa de 453,160 corresponde a $[2 \mathrm{M}+\mathrm{H}]^{+}$.

\subsection{Quantificação da genipina}

A quantificação foi realizada por meio de gravimetria, com a massa média de dois frascos coletores vazios e idênticos aos que armazenam a substância purificada e o conjunto. A massa de genipina obtida foi de:

$$
\mathrm{M}_{\text {ganipina }}=0,1379 \mathrm{~g}
$$

O rendimento em massa da extração é dado por:

$$
\mathrm{R}(\%)=\left(\mathrm{M}_{\text {genipinal }} / \mathrm{M}_{\text {polpa }}\right) * 100=(0,1379 / 97,42) * 100=0,1416 \%
$$

A estimativa para o rendimento do processo extrativo em base seca foi de:

$$
\begin{gathered}
\mathbf{M}_{\text {polpa seca }}=97,42-70 \%=29,226 \mathrm{~g} \\
\mathbf{M}_{\text {ganipina }}=0,1379 \mathrm{~g}
\end{gathered}
$$

O rendimento em massa seca da extração é dado por:

$$
\mathbf{R}(\boldsymbol{\%})=\left(\mathbf{M}_{\text {genipina }} / \mathrm{M}_{\text {polpaseca }}\right) * 100=(0,1379 / 29,226) * 100=\mathbf{0 , 4 7 1 8 \%} .
$$

\subsection{Reologia dos hidrogéis}

A partir da análise oscilatória em regime dinâmico foi possível caracterizar as amostras quanto à sua capacidade elástica, ou de armazenamento de energia, através da quantificação experimental das componentes do módulo complexo em função da frequência angular. Essa análise permitiu identificar a influência de fatores físico-químicos, tais como, a concentração de polímero/reticulante e a temperatura, no mecanismo de gelificação e inferir o seu efeito a nível da organização molecular.

O deslocamento do ponto de cruzamento quando $G^{\prime}(\omega)$ coincide com $G^{\prime \prime}(\omega)$ permite predizer se está ocorrendo aumento ou diminuição de massa molar (MM), bem como, o alargamento ou estreitamento da distribuição de massa molar (DMM) conforme mostrado na Figura 8.

Figura 8 - Relação da massa molar e das componentes do modulo complexo.

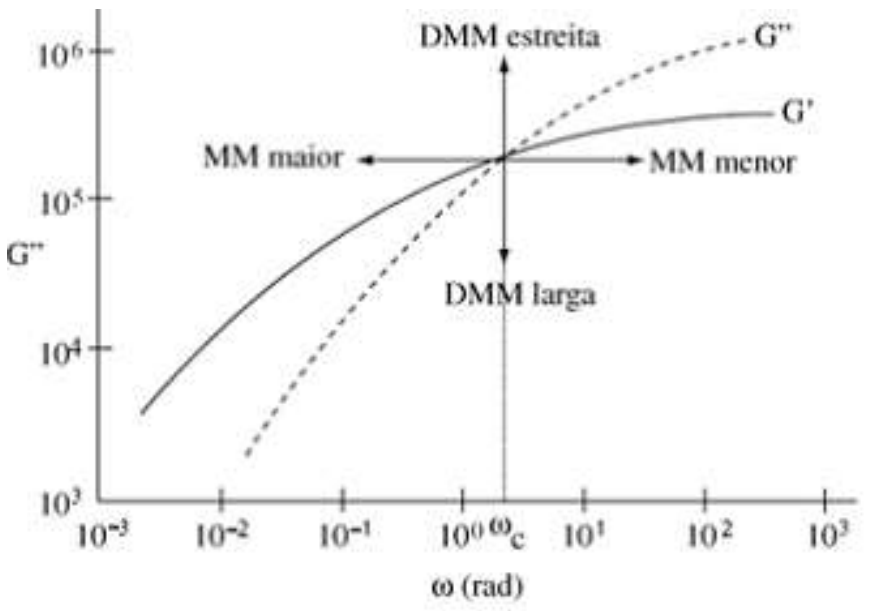

Fonte: Moura (2015). 
Foi observado que as curvas das componentes do modulo complexo das composições com menores teores de quitosana e genipina se cruzam e são deslocados para a direita, indicando um peso molecular menor e consequentemente viscosidade menor quando comparados as composições com maior teor de genipina e quitosana.

Nas composições com maiores teores de quitosana e genipina o cruzamento das curvas acontece mais para a esquerda, indicando um maior peso molecular e viscosidade. Esse dado era "previsível", visto que, um maior teor de quitosana e genipina na composição, favorece a reticulação e o aumento da massa molar do sistema.

Figura 9 - Curvas das componentes do modulo complexo em função da frequência. Composições (A), (B), (C) e (D).
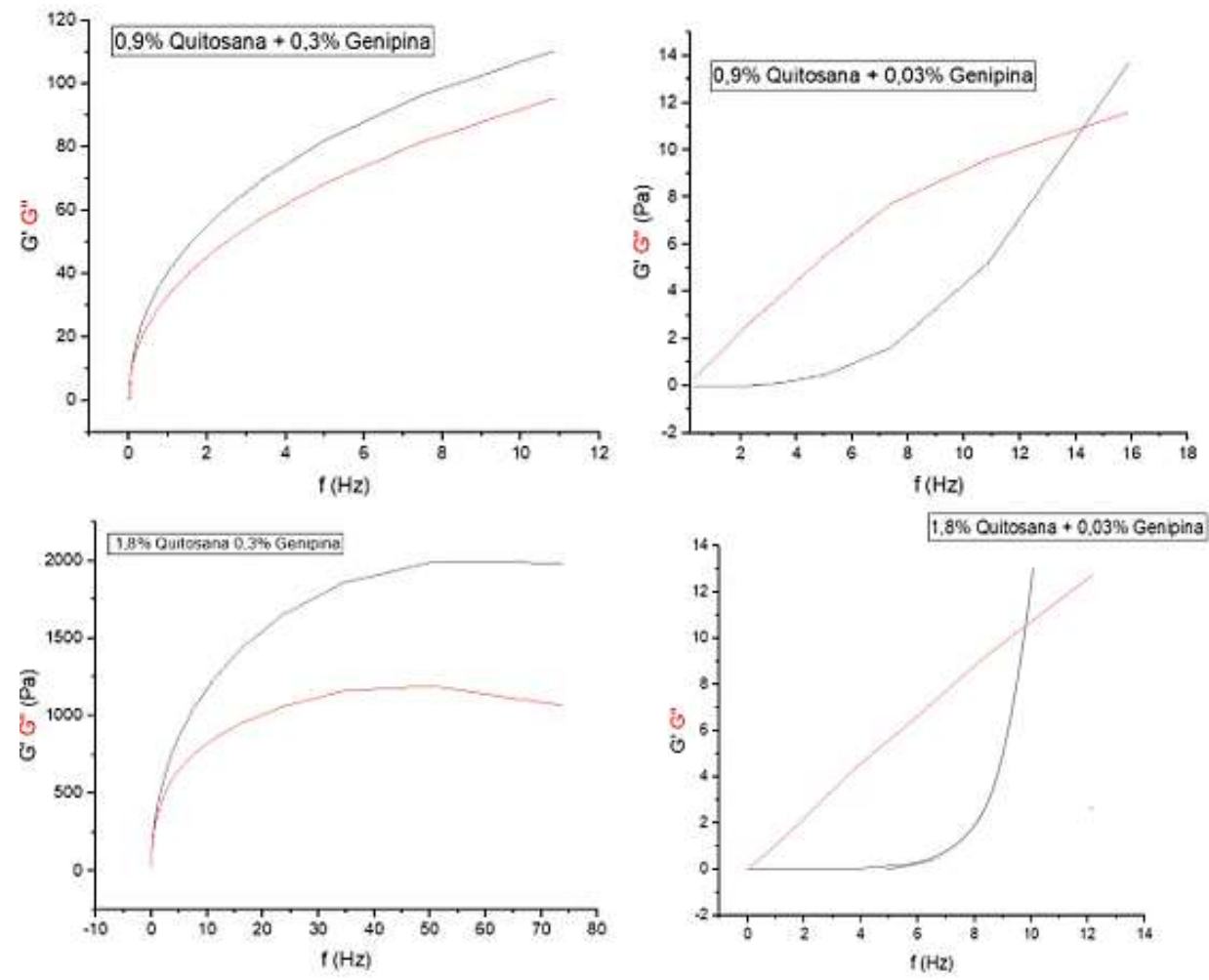

Fonte: Autores.

De acordo com as Figuras 9 e 10, foi observado para as composições com (0,03\%) de genipina, um comportamento típico de uma solução polimérica concentrada. Para valores baixos de frequência, o comportamento é semelhante ao de um líquido devido à desorganização da rede.

Com teor de 0,3\% de genipina, as composições apresentaram perfil característico de um gel polimérico. Com o aumento da frequência, ocorreu a distorção da rede, com G' sobrepondo G', até se intersectarem, nesse momento, ficou definido o ponto de gelificação. O sistema apresentou uma resposta predominantemente sólida. Este comportamento reflete a existência de uma rede tridimensional em que, quanto maior o valor de G', maior é o carácter sólido do gel e as deformações serão elásticas ou recuperáveis (Moura, 2015; Manzoor et al., 2018). 
Figura 10 - Curvas das componentes do modulo complexo em função da frequência. Composições $(\mathrm{E}),(\mathrm{F}),(\mathrm{G})$ e $(\mathrm{H})$.
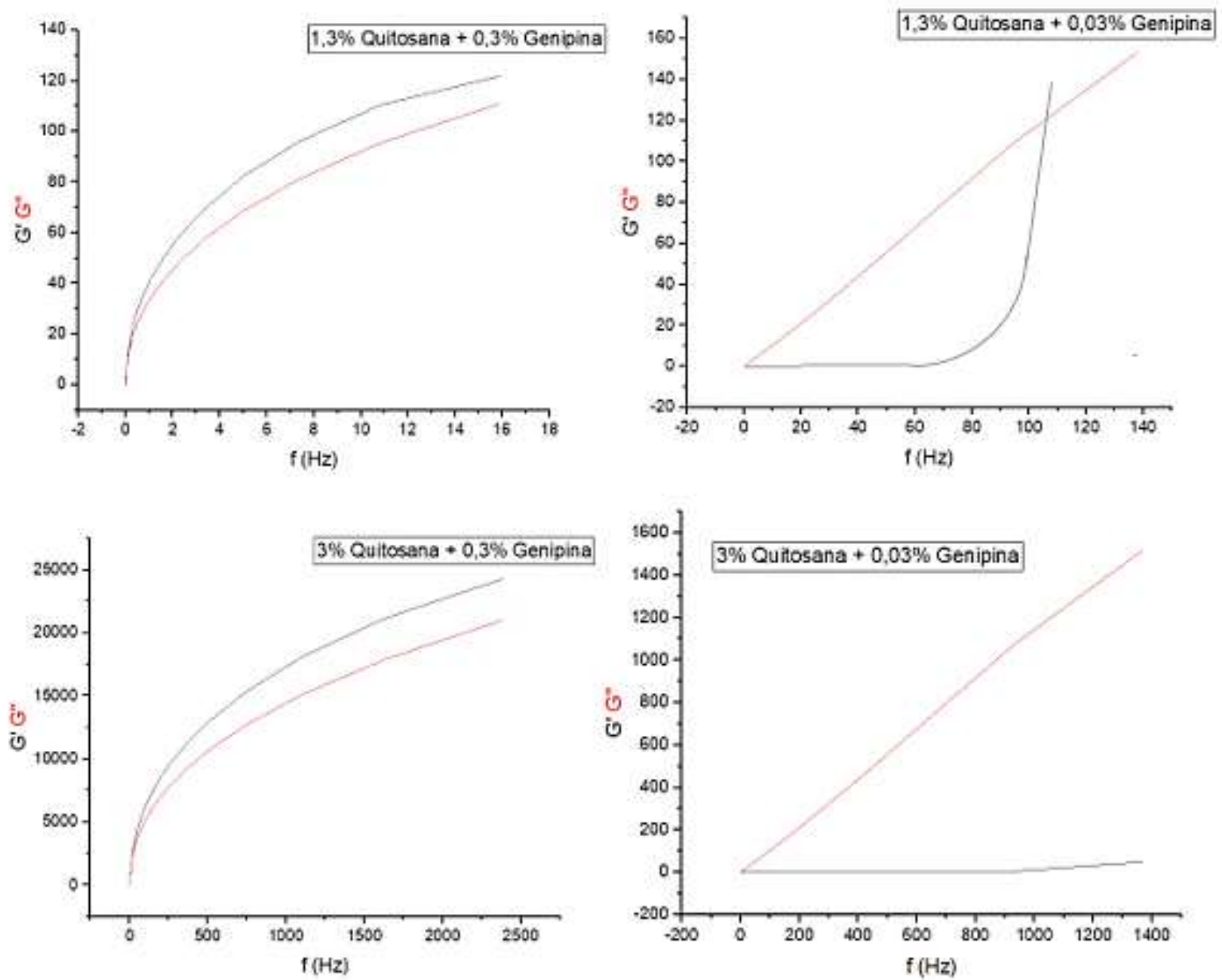

Fonte: Autores.

De modo geral, foi percebido em ambos os gráficos (Figuras 9 e 10), que as composições com um maior teor de genipina, manteve a curva de G' acima de G” ao final do ensaio, demostrando uma tendência de comportamento elástico dos hidrogéis. Resultados semelhantes foram observados por Moura (2015), onde o uso da genipina, como agente reticulante, em hidrogéis de quitosana, favoreceu o aumento da massa molar dos géis, o que foi atribuído ao surgimento das ligações cruzadas proveniente da genipina.

\subsection{Calorimetria Exploratória Diferencial (DSC)}

A calorimetria exploratória diferencial (DSC) foi realizada em quatro das oito composições, pois, apenas as composições com teores de $0,3 \%$ de quitosana apresentaram um comportamento reológico típico de um gel, as demais amostras possuem comportamento de uma solução polimérica.

A Figura 11 ilustra os resultados de DSC dos hidrogéis de quitosana e genipina. 
Figura 11 - DSC dos hidrogéis de quitosana e genipina.

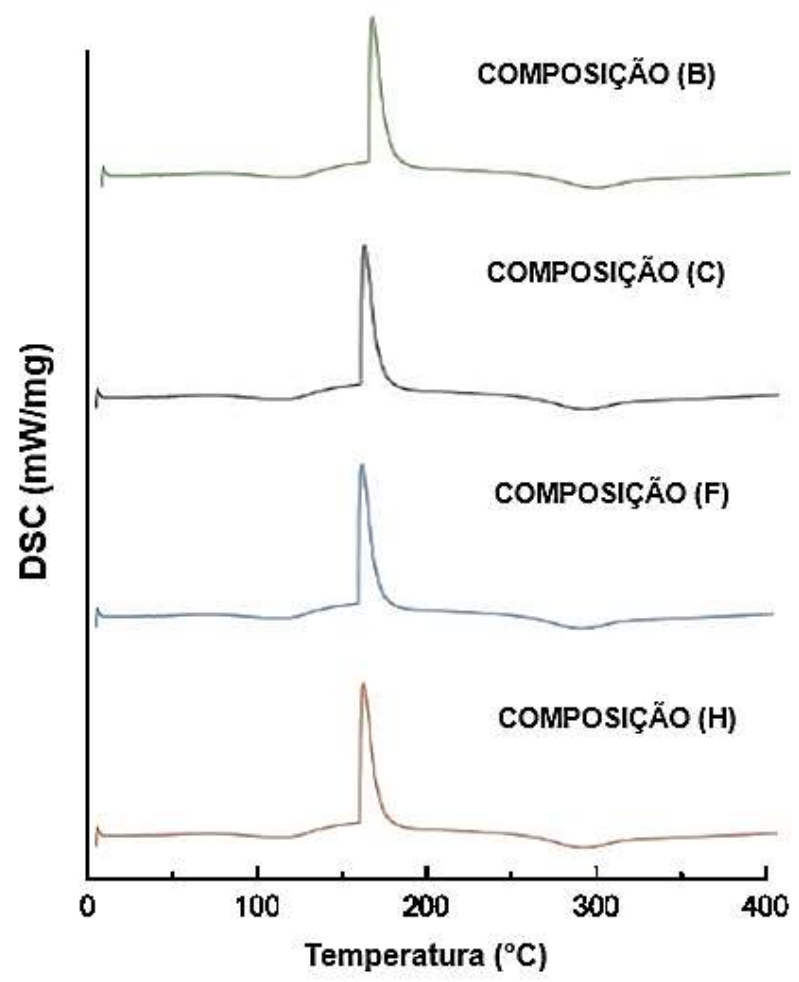

Fonte: Autores.

Para todas as composições analisadas, foi observado um pico exotérmico em $127^{\circ} \mathrm{C}$ e um pico endotérmico a $173^{\circ} \mathrm{C}$, este último, associado à temperatura de fusão cristalina da genipina, deslocada para temperatura mais alta, devido à interação covalente com as cadeias de quitosana, e uma exotérmica a $295^{\circ} \mathrm{C}$ (Dimida et al., 2015; Klein et al., 2016). Como esperado, o pico de degradação para a amostra seca de genipina-quitosana está a $290^{\circ} \mathrm{C}$, isso pode indicar que a reticulação de genipina estabiliza a estrutura hidrogênio, porque pode criar pontes químicas entre a espinha dorsal da quitosana (Klein et al., 2016).

\subsection{Absorção de água dos hidrogéis}

A Figura 12 mostra o resultado dos valores de absorção de água dos hidrogéis e o efeito da concentração de genipina na quantidade de água absorvida. 
Figura 12 - Absorção de água (\%) nos hidrogéis de quitosana e genipina. Q = quitosana; G = genipina.

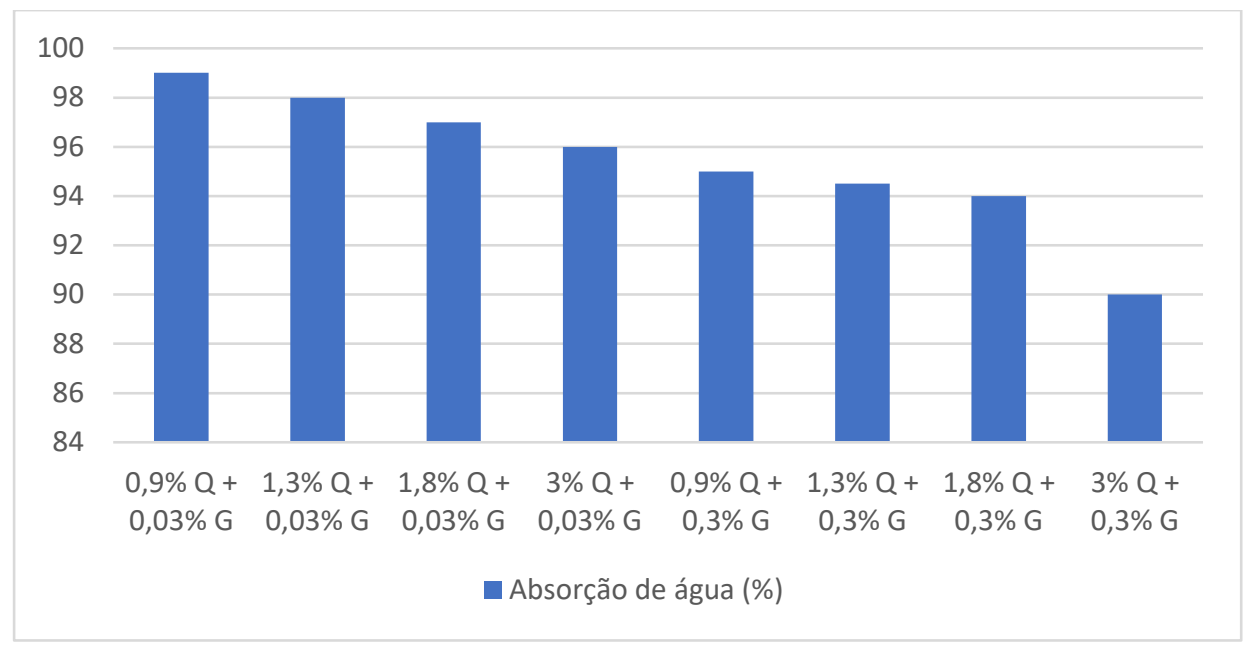

Fonte: Autores.

A capacidade de absorção de água é altamente dependente do grau de reticulação dos materiais, na medida que, quanto maior o grau de reticulação, mais rígida será a estrutura e menor a absorção de água. Porém, os hidrogéis são altamente hidrofílicos e por esse motivo apresentam altos valores de absorção de água independente do grau de reticulação (Pellá et al., 2018).

De acordo com os resultados, foi observado que as composições com teores de genipina em 0,3\% apresentaram um menor valor de absorção de água, quando comparadas as demais composições. Possivelmente, devido ao maior grau de reticulação, o que dificultou a capacidade de absorção de água nos hidrogéis. De modo geral, a genipina utilizada atuou como agente reticulante do sistema, resultando na diminuição da absorção de água dos hidrogéis. Estudos semelhantes foram realizados por Pellá et al., 2018 e Manzoor et al., 2018.

\section{Conclusão}

A genipina obtida pelo método de baixo custo proposto neste trabalho gerou um material com excelente grau de pureza e com rendimentos satisfatórios quando comparados aos valores encontrados na literatura, mesmo utilizando um processo mais simples do que os relatados. A partir dos resultados de reologia, foi observado que quanto maior o teor de genipina e quitosana, maior será a viscosidade do material e consequentemente maior massa molar. Notou-se que as composições com uma maior quantidade de genipina formou-se um perfil reológico característico de um gel polimérico, enquanto valores baixos do agente reticulante proporcionou um perfil típico de uma solução polimérica, evidenciando a necessidade de uma maior quantidade de genipina na composição de hidrogéis de quitosana - genipina. Para melhor compreender a aplicabilidade dos hidrogéis reticulados com genipina, recomenda-se como trabalhos futuros a preparação de scaffolds de quitosana-genipina e sua caracterização reológica e mecânica.

\section{Referências}

Bellé, A. S. (2017). Extração de genipina a partir do jenipapo (Genipa americana Linnaeus) para imobilização de enzimas. 171 p. Dissertação (Ciência e Tecnologia de Alimentos) - Universidade Federal do Rio Grande do Sul.

Djerassi, C., Gray, J. \& Kincl, F. (1960). Naturally Occurring Oxygen Heterocyclics. IX. Isolation and Characterization of Genipin. J. Organic Chemistry, 25(12), 2174-7.

Chronopoulou, L. et al. (2018). A physico-chemical approach to the study of genipin crosslinking of biofabricated peptide hydrogels. Process Biochemistry, 70, 110-116. 
Craveiro A. A. \& Craveiro A. C. (2000). Membrana de quitina e quitosana para utilização em regeneração de tecidos e cicatrizações. Patente brasileira, PI 9805480-5A.

Dimida, S., Demitri, C., De Benedictis, V. M., Scalera, F., Gervaso, F. \& Sannino, A. (2015). Genipin-cross-linked chitosan-based hydrogels: Reaction kinetics and structure-related characteristics. Journal of Applied Polymer Science, 132.

Dong, Y. et al. (2014). Biotransformation of geniposide in Gardenia jasminoides to genipin by Trichoderma harzianum CGMCC 2979. Chinese Journal of Catalysis, 35(9), 1534-1546.

Estrela, C. (2018). Metodologia Científica: Ciência, Ensino, Pesquisa. Editora Artes Médicas.

Fan, Z., Qin, Y., Liu, S., Xing, R., Yu, H., Chen, X., Li, K. \& Li, P. (2018). Synthesis, characterization, and antifungal evaluation of diethoxyphosphoryl polyaminoethyl chitosan derivatives. Carbohydrate Polymers, 190, 1-11.

Francis, J.K. (1993). Genipa americana L.Jagua, genipa. Departament of Agriculture, Forest Service, Southern Forest Experiment Station, 58, 1-5.

Klein, M. P., Hackenhaar, C. R., Lorenzoni, A.S., Rodrigues, R. C., Costa, T. M., Ninow, J. L. \& Hertz, P. F. (2016). Chitosan crosslinked with genipin as support matrix for application in food process: Support characterization and $\beta$-dgalactosidase immobilization. Carbohydrate Polymers, 137 , 184-90.

Lee, K. Y.; Ha, W. S. \& Park, W. H. (1995). Blood compatibility and biodegradability of partially N-acylated chitosan derivatives. Biomaterials, 16, 12111216.

Manzoor, K., Ahmad, S., Soundarajan, A., Ikram, S. \& Ahmed, S. (2018). Chitosan Based Nanomaterials for Biomedical Applications. Handbook of Nanomaterials for Industrial Applications: Elsevier; 543-62.

Mima, S. et al. (1983). Highly deacetylated chitosan and its properties. Journal of Applied Polymer Science, 28, $1909-1917$.

Moura, M. (2015). Preparação e caracterização de hidrogéis de quitosano para administração por via injetável. Coimbra.

Neves, G. N. \& Meireles, M. A. A. (2018). Genipap: A new perspective on natural colorants for the food industry. Food and Public Health. 8, 21 - 33.

Zhu, Y., Zhao, B., Huang, X., Chen, B., Qian H, A. (2015). Substrate Fed-Batch Biphasic Catalysis Process for the Production of Natural Crosslinking Agent Genipin with Fusarium solani ACCC 36223. J. Microbiol. Biotechnol. 2015; 25:814-819.

Ornoff, D. M. et al. (2016). Co-fabrication of chitosan and epoxy photoresist to form microwell arrays with permeable hydrogel bottoms. Biomaterials, 74, 7788 .

Pellá, M. G., Lima-Tenório, M. K., TenórioNeto, E. T., Guilherme, M. R., Muniz, E. C., \& Rubira, A. F. (2018). Chitosan-based hydrogels: from preparation to biomedical applications. Carbohydrate polymers, 196, 233-45.

Pereira A. S. et al. (2018). Metodologia da pesquisa científica. UFSM.

Ramos-de-la-Penã, A. M. (2016). A review through recovery, purification and identification of genipin. Phytochem Reviews. 15, 37-49.

Rao, S. B. \& SHARMA, C. P. (1997). Use of chitosan as a biomaterial: Studies on its safety and hemostatic potential. Journal of Biomedical Materials Research, $34,21-28$.

Renhe, I. R. T. et al. (2009). Obtenção do corante natural azul extraído de frutos de jenipapo. Pesquisa Agropecuária Brasileira. 44,649 - 652.

Sun, Y. S. et al. (2018). Bone cell responses to a low elastic modulus titanium alloy surface immobilized with the natural cross-linker genipin. Surface and Coatings Technology, 350, 918-924.

Veslásquez, C. J., Rivas A., Ocanto, I. S. (2014). Obtención de genipina a partir de caruto (Genipa americana L.) dellano venezolano. Avances en Química. 9 , $75-86$.

Vunain, E., Mishra, A. K., \& Mamba, B. B. (2017). Fundamentals of chitosan for biomedical applications. Chitosan Based Biomaterials.

Wang, S.C. et al. (2011). Using orthogonal arrays to obtain efficient and reproducible extraction conditions of geniposide and genipin in gardenia fruit with liquid chromatography-mass spectrometry determinations. Journal of Food and Drug Analysis, 19(4), 486-494.

Winotapun, W. et al. (2013). One-enzyme catalyzed simultaneous plant cell disruption and conversion of released glycoside to aglycone combined with in situ product separation as green one-pot production of genipin from gardenia fruit. Enzyme and Microbial Technology, 53(2), 92-96.

Xu, J. et al. (2015). Genipin-crosslinked catechol-chitosan mucoadhesive hydrogels for buccal drug delivery. Biomaterials, 37, 395-404.

Yang, Y.S. et al. (2011). Transformation of geniposide into genipin by immobilized bglucosidase in a two-phase aqueous-organic system. Molecules, 16(5), pp.4295- 4304 .

Yao, C. K. et al. (2012). Porous chitosan scaffold cross-linked by chemical and natural procedure applied to investigate cell regeneration. Applied Surface Science, v. 262, p. 218-221.

Yu, S. et al. (2017). A novel pH-induced thermosensitive hydrogel composed of carboxymethyl chitosan and poloxamer cross-linked by glutaraldehyde for ophthalmic drug delivery. Carbohydrate Polymers, 155, 208-217.

Zhou, T. et al. (2005). Large-scale isolation and purification of geniposide from the fruit of Gardenia jasminoides Ellis by high-speed counter-current chromatography. Journal of Chromatography, 1100(1), 76-80

Zhu, Y., Zhao, B., Huang, X., Chen, B., \& Qian, H. (2015). A Substrate Fed-Batch Biphasic Catalysis Process for the Production of Natural Crosslinking Agent Genipin with Fusarium solani ACCC 36223. J Microbiol Biotechnol. 